\title{
La tradición en jaque. Una lectura desde la diferencia
}

\author{
Ana María Martínez de la Escalera
}

Se trata de problematizar la noción gadameriana de tradición desde la noción de memoria o experiencia de la memoria, tras su afinamiento en los últimos textos derridianos. Así, el trasfondo histórico-político de la problematización no será tratado como un mero apéndice contextual sino que cobrará toda su importancia al encarnar categorías o conceptos que hoy están siendo debatidos en varios foros. Me refiero a conceptos como los siguientes: lo público, lo comunitario, las memorias colectivas, la tradición en su relación con lo actual y lo viviente y finalmente la despolitización que estas nociones han experimentado en los últimos años a causa de circunstancias muy específicas. Estas circunstancias son en realidad experiencias inéditas que han socavado el optimismo racional pero han dejado permanecer un cierto desasosiego intelectual. Los autores trabajados junto a Gadamer son Hannah Arendt y Walter Benjamin, además de, como dije, Jacques Derrida.

In this paper the gadamerian concept of "tradition" is problematized by the use of "memory" and "memory as experience". The concept of "experience" acts out as a cathalyst which brings out the "historical" and the "political" dimentions of tradition as a memory experience. Thus a vocabulary is revisited; concepts of "public" (as in public opinion), "community", "future", "collective memory" and tradition are read, through a politically oriented reading, as "heteronomous events", contingent effects of human (political, economical, social, ethical) action (energeia). 

Ana María Martínez de la Escalera

Facultad de Filosofía y Letras, UNAM

\section{La tradición en jaque. Una lectura desde la diferencia}

"Los regímenes totalitarios del siglo xx han revelado la existencia de un peligro insospechado: la supresión de la memoria." Con esta frase que da inicio a su libro Los abusos de la memoria, escrito en 1995, Todorov resumía varias opiniones de muchos de sus polemistas contemporáneos. Primera, que debe leerse la cuestión de la memoria desde un horizonte de significación política. Y segunda, que de la politización de la memoria colectiva, se deducía un imperativo para Europa, el de revelar las políticas del olvido, es decir evidenciar el éxito operativo de las campañas sistemáticas, y casi siempre dirigidas desde el Estado, de obliteración y borramiento de las memorias colectivas. No bastaría, en este sentido, un programa para recordar las tradiciones de los pueblos víctimas del olvido. Por sí solas —o lo que es lo mismo en su dimensión inductiva según Gadamer argumentó- ellas dan lugar al espectáculo, académico o mediático, ${ }^{1}$ o como analizó Todorov a su exhibición —patética e inútil— en museos y monumentos de la

${ }^{1}$ A este respecto, es decir a las políticas de la memoria y del olvido en las sociedades del espectáculo, véase Kracauer, De Caligari a Hitler (1947) y Theory of Film (1960). 
ignominia. ${ }^{2}$ Es conocido que el uso del monumento, con su sólida fuerza de estereotipia catacrética, ${ }^{3}$ propia del lugar común al que nadie otorga ya un significado activo, distancia el acontecimiento rememorado del observador, provocando en él una actitud de respeto resignado. ${ }^{4}$ Arrancados por el poder enfático ${ }^{5}$ del monumento del entorno de la historia humana viva, los perseguidos son así sacralizados y convertidos en víctimas ejemplares de la monstruosidad del enemigo, de su inhumanidad; despojos abandonados tras la batalla, ruinas que a todos avergüenza mirar. ${ }^{6}$

${ }^{2}$ La forma monumento es la puesta en acción de una ontologización de restos, una suerte de sacralización de fragmentos cuyos efectos son la deshistorización y la despolitización de los acontecimientos. La ontologización de restos pudo parecer en un momento una respuesta política. Al respecto Kracauer argumentaba la potencialidad "redentora" de la relación entre imagen cinematográfica y memoria. Véase Kracauer, De Caligari a Hitler (1947) y Theory of film (1960). La expectativa de la redención saca sin embargo de la historia humana no sólo al acontecimiento violento sino a su representación cinematográfica y le resta fuerza crítica al espectro, aquello que llamaríamos su fuerza de justicia. El espectro es también, en esta ocasión no sólo demanda de justicia sino acto de desobediencia. Véase sobre el tema del monumento: Friedrich Nietzsche, Sobre la utilidad y los perjuicios de la historia para la vida, Madrid, EDAF, 2000. A propósito del espectro, véase Derrida 1995. Y sobre Kracauer y la redención mediante el fragmento, véase Traverso 2004.

${ }^{3}$ La catacresis es una figura retórica que ya marchita por el uso, ha perdido originalidad y eficacia y se literaliza, se vuelve un lugar común, un cliché sobre el que ningún intérprete u observador se interroga o pone en cuestión. Es la base de la política del olvido.

${ }^{4}$ En efecto, respeto al lugar común y a lo común del lugar que se celebra como "dado" y por ello inevitable.

${ }^{5}$ El énfasis es una figura retórica que, como Beristáin refiere en su diccionario, evita la expresión de un contenido indeseado o peligroso sustituyéndolo con un contenido inocuo o atenuante. En el caso del monumento, se subraya la ejemplaridad en detrimento de la violencia contra el enemigo que se conmemora en él. Véase Helena Beristáin, Diccionario de retórica y poética, México, Porrúa, 1997.

${ }^{6} \mathrm{El}$ genocidio judío perpetrado por los nazis nos ofrece un ejemplo paradigmático. En el curso de los años sesenta la "puesta en muerte" adquirió paulatinamente un estatus sagrado. Se le dio el nombre bíblico de Shoá, que rubricaba su absoluta singularidad y remitía a una concepción religiosa de esta parte de la historia de los hombres: el acontecimiento fue declarado inconcebible, indecible, inmostrable, destinado a un más allá metafísico que por naturaleza se sustraía a cualquier comprensión. Véase Brauman y Sivan 1999. 
La memoria y la tradición, una vez reducidas a despojos no pueden ya aspirar a la reflexión; quedan así convertidas en materia inerte, imágenes tan vacías como los sloganes de una campaña política del pasado. Así es como el monumento que es un hecho de tradición tanto como antaño lo fue la figura del héroe épico, opera en el espectador una respuesta si se quiere irracional, la oposición antagónica entre amigos y enemigos, entre buenos y malos, entre lo sagrado absoluto y lo execrable, de tan desafortunadas consecuencias despolitizadoras.

Pero, la memoria y la tradición no son ruinas para ser contempladas o recorridas por los turistas del espíritu. Configuradas por "momentos de la vida de la experiencia" (Gadamer) de una comunidad no se encuentran encastillados ni en una herencia ni en una lengua. Según advierte Derrida en El monolingüismo del otro, lo cierto es que el pensamiento de la experiencia revela que siempre hay "mucho más que una lengua" en juego. Una lengua siempre se distingue de otra, una política siempre se distingue de la otra: una memoria siempre se distinguirá de otra memoria. Luego la experiencia de la tradición y de la memoria son heterogéneas. La heterogeneidad que caracteriza el legado, la tradición o la memoria colectiva es una fuerza que no sólo radica en sus contenidos, es decir en el noema recordado, una especie de "eso ha sido" evidente. La heterogeneidad o diversidad son también noéticas: pero son operaciones colectivas o sociales de sentido. Éstas comportan decisiones contingentes: elecciones, selecciones, edición y montaje del material de la experiencia, uso de formas de conservación y formas de transmisión: y cualquiera de estas operaciones se inscriben no sobre una materia pura u originaria de "hechos" sino, más bien, sobre una operación anterior de inscripción del material recordado. Luego entonces, lo que es preciso recordar, siguiendo a Todorov, no son "cosas pasadas". Son las maneras o modos por los que el olvido consiguió, escribiendo sobre los recuerdos como en un espectral 
modo maquínico de sobreescritura, obliterar una narración, una historia, una tradición; en suma, unos momentos de vida. Estas maneras configuran e instituyen políticas del olvido que es posible describir con el mismo cuidado con el que se describen las políticas de la memoria pues ambas manifiestan la verdadera fuerza de la tradición: una materialidad que obra en prácticas, instituciones, comportamientos intersubjetivos (formas de saber, relaciones de poder y formas de la subjetividad según lo planteó Michel Foucault). Materialidad que opera e interviene a través de experiencias que no pueden reducirse a meros "momentos de vida" según los llamó Gadamer. Estudiosos de diversos campos de las ciencias sociales y humanas concuerdan en que hoy en día la materialidad de la experiencia en relación con la memoria y la tradición se ha tornado un espacio de intervenciones políticas, además de psicológicas, estéticas o culturales. La materialidad no es lo físico sino las formas de intervención. La política del olvido ha sido conducida desde el siglo xx hasta nuestros aciagos días como parte sustancial de las estrategias del coloniaje, del totalitarismo y del neocoloniaje que Europa ha instrumentado sobre el resto del mundo (sin olvidar las dictaduras del llamado Tercer Mundo, producto a su vez de la tecnología de colonización). ${ }^{7}$ Pensar la tradición y la memoria a partir de esta política del olvido evidentemente politiza la cuestión, pero además la piensa desde su conflictividad constituyente. O sea que la política del olvido se erige siempre en contra de una memoria que se decreta (como parte de los procedimientos de la misma tecnología y de ahí el nombre de política) como antagónica y enemiga.

\footnotetext{
${ }^{7}$ Habría que pensar en la emigración, la evacuación forzada de territorios, la expulsión y la reinstalación de los habitantes nativos y finalmente su muerte como estrategias de olvido absolutas de una lengua y una historia específicas. Además de decretar el olvido y la muerte se procede a llevarlo a cabo con gran cuidado en los detalles como el Estado israelí muestra en sus campañas contra los palestinos. Aquí en América habría que recordar las batidas del gobierno argentino en contra de los indígenas fueguinos.
} 
Entre el fin de la segunda guerra mundial y la proclamación del Estado judío soberano, la catástrofe judía fue enarbolada como una bandera que presidía la lucha por el reconocimiento del Estado de Israel. El recuerdo de los campos de exterminio fue una palanca psicológica y política a la vez que permitió legitimar el diseño de Ben Gurión. La expulsión metódica de setecientos mil palestinos fue ocultada por la emancipación de los mártires europeos. El memorial Yad Vashem, erigido unos años más tarde, testimonia ese borramiento de una memoria por otra. El lugar que alberga el centro de investigaciones y el museo fue construido sobre las ruinas de un poblado palestino arrasado durante la guerra de $1948 .{ }^{8}$ Así, hablar de la tradición y la memoria sin relacionarlas con su "exterior constitutivo" no sólo parece ser un olvido sin importancia sino que puede proceder de una lectura que despolitiza el material estudiado. La insistencia política resulta completamente legitimada si recordamos los abusos ya no ideológicos sino sentimentales que se han cometido en nombre de las memorias de las víctimas: últimamente hemos visto en los medios masivos los testimonios y la memoria de los perseguidos como si fuesen ejemplos de sufrimiento indecible, inexplicable, incomprensible. Reducir la memoria a lo incomunicable es un ejemplo típico de la despolitización conducida por los medios y de la puesta en crisis o confusión de valores que es su contexto operativo. Deshumanizada, fuera de este mundo la memoria y la tradición sólo aspira a provocar una muda compasión y, quizás, a arrancar algún suspiro del espectador más sensible. A esto llamamos desactivación de la tradición, cancelación de la fuerza de resistencia que reside en la memoria y que puede reactivarse una vez que le son devueltas su historicidad y su lengua propias.

\footnotetext{
${ }^{8}$ Véase Brauman y Sivan 1999, 31.

${ }^{9}$ Véase Laclau 2006, 10-16.
} 
Todorov argumenta en el libro citado que también se abusa de la memoria cuando se la utiliza como una estrategia de violencia contra el otro. Sin embargo, esta violencia no es ajena ni a la tradición ni a la memoria colectiva. Pero por cierto que hemos hecho como si no estuviera allí. Si nos remontamos al pensamiento de Humboldt encontramos (tempranamente) una preocupación por esta lógica violenta que instituye la tradición y las relaciones entre las lenguas. Para él, entrar en contacto con otra tradición supone una acción o ejercicio guiados por una suerte de egológica por la cual la propia lengua recubre al otro, que mediante la estructura formal del diálogo inmediatamente se ubica (gramaticalmente) como un tú. "Por el mismo acto por el que el hombre hila desde su interior la lengua, se hace él mismo hebra de aquella, y cada lengua traza en torno al pueblo al que pertenece un círculo del que no se puede salir si no es entrando al mismo tiempo en el círculo de la otra." 10 Tal entrada es problemática, sin embargo. Aunque aprender una lengua extraña comporta "la obtención de un nuevo punto de vista en la propia manera de entender el mundo", "esto no siempre se logra" ya que a "toda lengua nueva se le superpone [...] la propia manera de ver el mundo e incluso la propia manera de concebir el lenguaje". ${ }^{12} \mathrm{El}$ texto humboldtiano es el primer recordatorio, todavía en ciernes, de la problematicidad de la relación con la pluralidad pensada o reducida a la forma yo-tú del diálogo. ${ }^{13}$

${ }^{10}$ Humboldt 1990, 83.

${ }^{11}$ Ibidem.

${ }^{12}$ Ibidem.

${ }^{13}$ En "Las voces del otro" Carlo Ginzburg analiza la Historia de las islas Marianas del jesuita Le Gobien, en la cual se introduce el discurso de un líder nativo, Hurao. Este discurso está inspirado en un famoso fragmento de Tácito en el que da voz a Calgaco, líder de los caledonios. Aún en un texto monológico como es un discurso se cuelan otras voces disonantes, en este caso procedentes de la tradición. Basado en el propio principio jesuítico de la accomodatio de la carta de Pablo (1 Cor 9: 20), el escritor se adapta al otro pero no puede evitar, en la escritura, que el dialogismo (Bajtín) haga presa de su pluma sin que él lo note. De hecho, 
La estructura lógico-gramatical yo-tút ${ }^{14}$ reduce la diferencia (con los otros) a interlocución, excluyendo a los terceros al privilegiar (mediante el reconocimiento o interpelación) al tú. El otro pierde así su singularidad, su fuerza radical de advenimiento (Derrida) y se torna lo acomodado. La interpelación que actúa en la dinámica de tipo buberiano yo-tú no permite mostrar la diferencia que interfiere (política y azarosamente) en la relación con todos los otros; es además una interpelación discriminadora que conserva la desigualdad (egológica) de cualquier relación del tipo yo-tú. El intercambio entre tradiciones es para Humblodt, que por supuesto lamenta la desigualdad que ello supone, una experiencia mediada por la apropiación (reconocimiento) de la diferencia y su conversión en un "propio". Desde luego, Humboldt planteaba a su tiempo y al nuestro un grave problema: la "cuestión del otro". Otro que no debía ser ni el resultado de una apropiación o reconocimiento ni la sacralización de otro incognoscible, sublime. Ni dominación ni teología: el otro radical no debe ser un tú reconocido por el yo, y por lo tanto reapropiado pero tampoco debe ser esa singularidad inexplicable producto a su vez de su exclusión del género humano y la comunicación. El deseo nacionalista

Le Gobien expresa la profunda ambigüedad que compartía con su orden religiosa respecto a la civilización europea. El texto del jesuita está ambientado en una campaña de colonización contra la cual la Compañía tiene serias críticas pero también intereses comunes. Como Tácito en su momento, la Compañía cree que Europa (Roma en el primero) ha perdido el rumbo civilizatorio y que el salvaje es menos bárbaro que el civilizado. La accomodatio, que es un principio ético-político al que el jesuita apela en estas condiciones de colonización; es sin embargo para nosotros un principio de teoría literaria y de política de la escritura. Incluso la intención crítica contra lo propio puede cancelar que se la dirige desde la propia tradición y no desde la del otro. Así el salvaje es más humano que el propio europeo pero desde los criterios europeos que se hacen pasar como universales. Véase Carlo Ginzburg, Relaçoes de força. História, retórica. Prova, Schwarcz, São Paulo, 2002, pp. 80 y ss.

${ }^{14}$ Conviene aquí recordar la advertencia que Nietzsche dirigió a sus contemporáneos en el sentido de que pensamos desde la tiranía del lenguaje, es decir, desde la estructura lógico-gramatical de la lengua, la cual entre otras cosas ostenta la virtud de volverse transparente. El filósofo suele ser ciego a esta tiranía sobre su propio pensamiento. 
quizás inspiró en el pensamiento otros problemas que excluyeron en los autores alemanes contemporáneos a Humboldt la preocupación por la alteridad. Llegado el siglo xx con sus experimentos totalitarios, el desinterés parece poco excusable. Así Gadamer, testigo de un ejemplo exitoso de invención de la "cuestión del otro" (cuestión judía, gitana, polaca, eslovena) sin embargo trató de borrar la problematicidad, es decir el problema político, detrás de la instrumentación burocrática e ideológica de la "cuestión". Polemizando con Humboldt, Gadamer escribe que según la experiencia hermenéutica haber aprendido y comprender una lengua extraña - este formalismo del poder hacer- no quiere decir más que estar en situación de hacer que lo que se dice en ella sea dicho para uno. Este ejercicio, continúa, es un dejarse captar por lo dicho, y esto no puede tener lugar si uno no integra en ello su propia acepción del mundo y del lenguaje. Pero esta integración no le causa problemas. Si recurrimos a la historia veremos que el interés por otras tradiciones aparece como una suerte de deseo intelectual que se acrecienta cuando algún país europeo se interesa a su vez en otra cultura. Este interés no parece brotar únicamente del deseo de aprender; más bien acompaña las campañas colonizadoras de Europa. Así el interés por las tradiciones indígenas; prueba de ello los libros que se han escrito durante la conquista y la colonización. Las novelas escritas por ingleses sobre la India, sobre África, etc. La cuestión del otro parece corresponderse con las campañas de conquista y desposesión. Esta tensión en el origen de la cuestión del otro debe integrarse al análisis. En efecto, es la relación lenguaje y mundo, como sugiere Gadamer, lo que debe pensarse, sólo que este estar-en-el-mundo del hombre no debe responder a una orientación abstractiva como él sugiere que hizo Humboldt, sino a una reflexión sobre la experiencia que escape al empobrecimiento en que la modernidad la ha hundido. ${ }^{15}$

${ }^{15}$ Véase Gadamer 1997, 526-547. 
En el concepto de la experiencia y la esencia de la experiencia hermenéutica, H. G. Gadamer apunta al carácter esquemático de la noción cuya utilización se circunscribe a lo empírico y argumenta la necesidad de pensar nuevamente esa noción. Escribe cómo la postura empirista que "hace de la percepción" que él determinará como transida por la vida de la lengua una mera "cosa externa y orientada a la mera corporalidad" será la razón de una reducción simplona ${ }^{16}$ que se volverá el fundamento de toda experiencia ulterior. ${ }^{17}$ Ahora bien, tal reducción no pertenece únicamente a la teoría sino al prejuicio, a la ideología, a la manera en que los individuos viven su relación con los otros y con el mundo. En efecto, podría decirse que a esa noción de experiencia le hace falta historia, una historia que la devuelva a un momento decisivo del desarrollo de Occidente, es decir a la modernidad. Para Gadamer sin embargo el empobrecimiento es teorético. El pensador alemán, quien insiste en que no debería haber una teoría de la experiencia que no tomara en cuenta la historia y por consiguiente el comprender, deshistoriza (o si se prefiere despolitiza) a su vez las razones de esa ausencia de teoría. Gadamer presenta la ausencia de una teoría como un "momento" de la tradición, entendiendo por esta última una serie de escritos —erróneos por lo demás o insuficientes- que van desde Aristóteles, pasando por Hegel hasta su propia contribución hermenéutica al asunto. En sentido estricto, la experiencia misma no es interrogada para dar cuenta de la imposibilidad (moderna) de una teoría (moderna) de la experiencia que no fuese simplemente negativa. ${ }^{18}$

\footnotetext{
${ }^{16}$ Experiencia cuyo "sustrato se percibe de una manera simplemente sensible" (Gadamer 1997, 422).

17 Véase Gadamer 1997, 422.

${ }^{18}$ En este sentido puede decirse que en Walter Benjamin se encuentra una teoría de la experiencia que va más allá de lo meramente negativo, es decir que además de mostrar la insuficiencia de la definición de experiencia en los escritos filosóficos, demuestra cómo la vida social fetichizada, efecto del capitalismo, que no permite al individuo relacionarse consigo mismo y con su pensamiento si no a partir de una imagen (alegoría) empobrecida de sí mismo (sin lengua y sin historia),
} 
De Husserl, Gadamer aprueba la intención de retroceder a la génesis del sentido de la noción de experiencia con el fin de superar la idealización por la ciencia. Pero sabe como el primero que "la pura subjetividad trascendental del ego no está dada realmente como tal sino siempre en la idealización del lenguaje que es inherente a la adquisición de experiencia y en la que opera la pertenencia del yo individual a una comunidad lingüística" ${ }^{19}$ En la experiencia entonces se atraviesa una lengua y una comunidad, una comunidad de lengua y un deseo de comunicarse con los otros. Pero nos preguntamos: $i y$ las restantes comunidades de hablantes con las que seguramente entramos en contacto, y las otras lenguas pueden ser excluidas del análisis?, ¿y la diversidad, como hubiera dicho Humboldt, ésta dónde queda en el análisis gadameriano? 20

Para Humboldt la diversidad no es sólo el efecto de la "individuación", ni tampoco la "individuación" debe entenderse como un principio o una categoría a la manera kantiana sino, valga la redundancia, la diversidad es un asunto de experiencia, que radica en los avatares de la vida misma de las lenguas, o lo que es lo mismo, es la respuesta a la dimensión kairológica de la experiencia, a la oportunidad, a la ocasión, a la contingencia y azarosidad de lo que es. La diversidad es un rasgo constitutivo de las lenguas y de las tradiciones a ellas ligadas: es esta lógica agonal de la memoria que se erige para borrar la otra. ${ }^{21}$ Humboldt permite pensar que el problema de hasta qué punto es posible un empleo puro de nuestra razón por encima del prejuicio, sobre todo del prejuicio "verbalista", no es simplemente un asunto teórico o de historia de una tradición de pensamiento. El prejuicio no sólo es positivo para la

puede ser, al mismo tiempo la ocasión para el pensamiento y la acción críticos. Kracauer, contemporáneo de Benjamin hizo también, a diferencia de Gadamer una lectura política de la experiencia y de la ausencia de su teoría.

${ }^{19}$ Gadamer 1997, 422.

${ }^{20}$ Ibidem, 421-439.

${ }^{21}$ Véase Brauman y Sivan 2000, 31. 
comprensión (de una comunidad dada respecto de sí misma) como insiste Gadamer; el prejuicio debe medirse a partir de la experiencia de la diversidad y de la tensión que esa diversidad genera. Es, pues, la tensión y sus problemas lo que debe pensarse y no, en todo caso, lo positivo del prejuicio para la comprensión pensada como una apropiación-interpelación de lo otro como tú. Aquí salta a la vista que lo que debe cuestionarse es la relación egológica-dialógica del yo-tú y la política (colonialista) de la lengua que ella preconiza.

\section{REFERENCIAS}

Brauman, Rony y Eyal Sivan, 1999. El elogio de la desobediencia, Buenos Aires, FCE.

Derrida, Jacques, 1995. Espectros de Marx, El estado de la deuda, el trabajo de duelo y la Nueva Internacional, Madrid, Trotta.

—, 1996. Le monolinguisme de l'autre, Paris, Galilée.

GadAmer, Hans-Georg, 1997. Verdad y método I, Salamanca, Sígueme.

Humboldt, Wilhelm von, 1990. Sobre la diversidad de la estructura del lenguaje humano y su influencia sobre el desarrollo espiritual de la humanidad, Barcelona, Anthropos.

Laclau, Ernesto, 2006. Misticismo, retórica y política, Buenos Aires, FCE.

Michelfelder, Diane P. y Richard E. Palmer, 2006. Dialogue and deconstruction. The Gadamer-Derrida Encounter, New York, State University of New York Press, 13.

Todorov, Tzvetan, 2000. Los abusos de la memoria, Barcelona, Paidós.

Traverso, Enzo, 2004. Cosmópolis, México, unam. 